\title{
ESTATUTO DO IDOSO E DIREITOS HUMANOS CONTRIBUINDO NA FORMAÇÃO DA CRIANÇA E DO ADOLESCENTE
}

\author{
STATUS OF ELDERLY AND HUMAN RIGHTS \\ CONTRIBUTING TO THE FORMATION OF THE CHILD AND \\ ADOLESCENT
}

\author{
Fabiane Maria Schoab ${ }^{1}$ \\ Édina Claudia Lima Fernandes Seremeta ${ }^{2}$ \\ Karini de Santana ${ }^{3}$ \\ Maria Iolanda de Oliveira ${ }^{4}$ \\ Neoli Cristina Semchechem Gruczka ${ }^{5}$ \\ Andressa Pacenko Malucelli ${ }^{6}$
}

\begin{abstract}
RESUMO
À medida que se busca compreender a temática em relação aos Direito Humanos, referenciamos preferencialmente através do artigo, os direitos dos Idosos, previstas na Lei $\mathrm{N}^{\circ} 10.741$ de $1^{\circ}$ de outubro de 2003 Estatuto do Idoso. Salientando questões como qualidade de vida, longevidade, respeito, valorização da pessoa idosa e ainda sobre a permanência do desafio de se eliminar os preconceitos ainda existentes na sociedade. A partir da problematização dessa temática, apontamos a experiência do NASJEPI- Núcleo de Assistência Social Jurídica e de estudos sobre a Pessoa Idosa que desenvolve oficinas lúdicas para estudantes de escolas fundamentais. A importância de desenvolver este trabalho é causar reflexão sobre o processo de envelhecimento, contribuir na educação dos alunos, e ainda no seu desenvolvimento intelectual e social. Dessa maneira a geração jovem estará espelhando suas ações, tornando-se cidadãos ativos, comprometidos com a causa e promovendo um ambiente mais agradável de viver em sociedade.
\end{abstract}

Palavras-chave: Direitos Humanos. Estatuto do Idoso. Pessoa Idosa. Educação.

\begin{abstract}
As it seeks to understand the subject in relation to Human Rights, we mention preferably through the article, the rights of the elderly under Law No. 10,741 of October 1, 2003 - Elderly Statute. Highlighting issues such as quality of life, longevity, respect, and appreciation of the elderly still remain on the challenge of eliminating prejudices that still exist in society. From the questioning of this subject, pointed out the experience NASJEPICore Social and Legal Studies on the Elderly developing recreational workshops for students in elementary schools. The importance of developing this work is to cause reflection on the aging process, contribute to the education of students, and even in their intellectual and social development. Thus the young generation will be mirroring their actions, becoming active citizens, committed to the cause and promoting a more pleasant environment to live in society.
\end{abstract}

Keywords: Human Rights. The Elderly. Elderly. Education.

\footnotetext{
${ }^{1}$ Universidade Estadual de Ponta Grossa. Departamento de Serviço Social, Projeto de extensão Núcleo de assistência social, jurídica e de estudos sobre a pessoa idosa. Email: fabiane_schoab@ @otmail.com

${ }^{2}$ Email: c_seremeta@hotmail.com

${ }^{3}$ Email: karini3092@live.com

${ }^{4}$ Email: maria2672@uol.com

${ }^{5}$ Email: neolicristina@gmail.com

${ }^{6}$ Email: andressapacenko@hotmail.com
} 


\section{INTRODUÇÃO}

Diariamente nos deparamos com cenas de desrespeito em nossa sociedade, são crianças, adolescentes, adultos e idosos que não possuem a consciência sobre a diversidade étnica e as mais variadas necessidades das pessoas, sobretudo o reconhecimento dos direitos humanos. Compreende-se que isso ocorre devido ao não acesso à educação e civilidade, e por vezes não entendemos o significado de comprometimento e exercício de cidadania.

Cidadania segundo ALMEIDA (2005) "É o conjunto das liberdades que se expressa pelos direitos civis" à autora nos chama atenção nesta frase para a relação existente entre cidadania e direitos, ou seja, a cidadania pressupõe o acesso e expansão de direitos, tais como: acesso a informação, participação política, locomoção, liberdade de expressão, etc.

A questão dos Direitos Humanos é hoje, sem duvida, especialmente após a Declaração Universal dos Direitos Humanos, ainda um tema de caráter existencial, porém não mais limitado a questões individuais, já que assume importância fundamental para toda a humanidade. Por um lado, tem uma dimensão abstrata e universal que transcende as especificidades culturais, e representam avanço sócio-político e cultural, promovem a transformação das estruturas arcaicas e, ainda, promovem a conscientização popular no sentido do seu engajamento na transformação da sociedade em geral. Por outro lado, devemos admitir que os Direitos Humanos não podem ser vistos somente como algo abstrato, mas refletem a historicidade e a situação social específica da atualidade. (NASCIMENTO, 2001, p.12)

Partindo desse pressuposto, onde os Direitos Humanos são frutos de um passado que avança constantemente e transforma o mundo, no que diz respeito às relações sociais, buscamos dialogar também com um trecho do Artigo XXVI da Declaração Universal dos Direitos Humanos, onde menciona que “A instrução será orientada no sentido do pleno desenvolvimento da personalidade humana e do fortalecimento do respeito pelos direitos humanos e pelas liberdades fundamentais". Nota-se, portanto a importância do reconhecimento dos direitos na formação do ser humano, o qual contribuirá para uma sociedade mais justa, e conseqüentemente menos violenta e desigual. $O$ fato de termos liberdades fundamentais, refere-se à questão do pertencimento de todos por estes direitos, e não somente a uma classe abastada. 
As pessoas idosas são um típico exemplo de cidadão "esquecido", isto porque muito de suas praticas acabam sendo interferidas, causando-lhes o isolamento e caracterizando-os como inválidos. Dessa forma são impedidos de exercer sua autonomia.

A autonomia (capacidade de decidir) e a independência (capacidade de realizar algo por seus próprios meios) são princípios que muitos idosos precisam conquistar novamente, Eles são indicadores de saúde e também identificam idosos com envelhecimento bem sucedido. Assim, a sociedade deve ajudar a promover e preservar a autonomia e a independência dos idosos e deixar de considerá-los cidadãos de "segunda-classe". (ALMEIDA, 2005, p.14)

Importante destacar que a independência não pressupõe a desresponsabilização do estado no que concerne à proteção dos idosos, e responsabilizar os idosos que mediante sua autonomia eles têm que dar conta das necessidades que lhe são inerentes nessa fase da vida. Aqui independência traz a conotação de capacidade de ação humana informada e deliberada a partir do exercício crítico de cidadania.

Tendo em vista que o envelhecimento é um processo inerente ao ser humano, faz-se necessário que haja estratégias de inclusão para esta classe, considerando ainda que a participação na sociedade é fator de direito que deve ser garantido e preservado.

\section{ENVELHECIMENTO E DIREITOS DOS IDOSOS}

O envelhecimento populacional é um acontecimento recente, destacando a longevidade da população na história, sendo uma conquista alcançada nesse ultimo século, em especial nos países desenvolvidos. A população está envelhecendo em um compasso acelerado. Referir-se ao envelhecimento é apresentar as transformações que vêm acompanhadas de significativas mudanças demográficas, biológicas, sociais, econômicas e comportamentais.

A mudança demográfica proporciona alteração na pirâmide etária, que passa ser mais composta na sua base que antes era de jovens, passando a demonstrar no seu topo o número significativo de idosos.

Segundo Berzins (2003, pg. 21) "a espécie humana nunca viveu tanto, de 1900 a 1915 foram acrescidos mais de 10 anos na vida humana. Em 1950, a expectativa de vida, já era de 65 anos". Na década de 1980 o Brasil ainda era considerado um país de jovens, a partir da diminuição da taxa de natalidade e o aumento da expectativa de vida este quadro mudou o perfil da população. 
O IBGE (Instituto Brasileiro de Geografia e Estatística) revela com dados recentes que o Brasil está se tornando um país com menos crianças e mais idosos nas próximas décadas. A população com mais de 65 anos será equivalente a 7\% do total em 2013. Esse número deverá crescer para $26 \%$ em 2060.

Para esse aumento da faixa etária será necessária adotar mudanças que permitam um estilo de vida com qualidade, serão novos tempos, para novos projetos que precisam estar relacionadas na vida dos idosos.

É preciso pensar na integração do individuo idoso na comunidade de forma que este não seja desvalorizado, visto que vivemos em uma sociedade onde a juventude é privilegiada perante a velhice. O Brasil possui um aparato legal que contempla os princípios de garantia de direitos a pessoa idosa, com Estatuto do Idoso, Lei 10.741 que entrou em vigor em $1 \circ$ de outubro de 2003, foi um prêmio contemplado, composto por 118 artigos que definem garantias legais aos idosos.

No entanto faz-se necessário mais do que isso na busca da emancipação do idoso, devendo-se divulgar a sociedade conhecimentos sobre o processo de envelhecimento e como encará-lo, visto que nos próximos anos a tendência é uma modificação na pirâmide etária do país, o que desencadeara inúmeras transformações sociais e econômicas. Portanto, desenvolver é algo que deve ser perseguindo pela sociedade e estado, mediante políticas de atendimento desse segmento.

Saber reconhecer as potencialidades e dar o valor necessário aos idosos que passaram de 60 anos parece ser ainda um desafio, dificuldades que ainda estão relacionadas a uma cultura que desvaloriza e delimita o contexto social do idoso.

A população idosa e sua participação na sociedade devem ocorrer mediante processo de consciência de seu valor e de suas potencialidades, enquanto sujeito que participa da história, trabalhando na organização social, buscando soluções para a qualidade de vida, através de políticas públicas.

Para tanto e de modo especial, observar-se que em países periféricos a pobreza e desigualdade contrapõem a busca de um estilo de vida adequada à pessoa idosa, considerando como desafio para essa expectativa de vida e sua conquista humana e social.

Segundo Nascimento (2001, p.13),

A discussão sobre os Direitos Humanos nos leva, portanto, ao âmago de questões que nos afligem no cotidiano, especialmente em um país como Brasil, onde se observa um grande contingente de excluídos e ás necessidades humanas coletivas dos cidadãos e cidadãs. 
Sendo assim, é indiscutível a necessidade de se fazer compreender o discurso, quando se trata do tema direitos humanos, pois este tem o comando de nos levar até a essência de situações que nos interpelam cotidianamente de modo especial em um país como o nosso, onde a maior parte de sua população vive a margem da sociedade, não usufruindo de tais direitos.

O crescente avanço no envelhecimento da população estabelece uma alteração breve e eficaz nos rumos das políticas sociais que considere as demandas e necessidades dos idosos de hoje e dos que o serão amanhã.

Porém quando observamos as condições de vida dos idosos, logo nos deparamos com diversos desafios que os MESMOS enfrentam em seu dia a dia. Como serem respeitados quando se trata de ter condições de saúde, de transporte, de habitação, de sociabilidade, de reconhecimento e de participação social.

Outra percepção é a reflexão e análise do que está diante de nossos olhos, que nos exige a reconstrução das condições da vida humana, pois em nossa sociedade que esta em constante desenvolvimento ainda permanece um processo discriminatório.

Ao tratar dos conhecimentos construídos pela humanidade, omitimos aqueles que se referem à determinada fase da vida, os que fazem referência ao envelhecimento.

Art. 22. Nos currículos mínimos dos diversos níveis de ensino formal serão inseridos conteúdos voltados ao processo de envelhecimento, ao respeito e à valorização do idoso, de forma a eliminar o preconceito e a produzir conhecimentos sobre a matéria. (ESTATUTO DO IDOSO, 20O3, p.13)

O artigo deixa esclarece sobre a inclusão, em todos os níveis de ensino, de conteúdos sobre o envelhecimento, respeito e valorização do idoso, de modo a eliminar preconceitos e a aumentar os conhecimentos sobre o tema.

Abordar o tema na área da educação, falar sobre envelhecimento e os direitos dos idosos, onde os saberes pertencentes nas disciplinas escolares, junto aos alunos e professores, pretendem-se cultivar bases disciplinares.

Para tanto se faz necessário que induzam alunos e professores a atividades de pesquisa, sistematizando conhecimento na construção humana, demonstrando que a vida são os elementos constituintes do pensamento da cultura do processo de envelhecimento, tornar-se uma questão da qualidade educacional. 
Para tanto se faz necessário ter uma sociedade que ofereça oportunidades de participação social aos mesmos, o que pode ser possível, através de compromisso com o acesso a educação em todos os níveis, em todas as idades.

O fator, envelhecimento de forma saudável e com qualidade de vida, será um desafio para o século XXI, na medida em que se deve questionar como será o atendimento para as pessoas idosas que utilizarão de serviços referentes à área de saúde, entre outros atendimentos inerentes a pessoa humana, compreendendo-se como prioridade que o idoso tenha autonomia sendo fundamental e necessário que os idosos possam ter atendimento para quaisquer que sejam as suas necessidades, terem uma rotina cujos cuidados propiciem benefícios e uma vida mais saudável.

Sabe-se que ainda parte da população brasileira é composta por pessoas que não dispõem de condições financeiras mais elevadas e conseqüentemente não dispõem de acesso a bens de serviços necessários, aqueles que são de seus direitos fundamentais para gozar dos seus direitos de cidadania.

No que concerne a população idosa, ainda falta infra-estrutura básica que oportunize condições para uma boa qualidade de vida e melhor solidificação para esses atributos.

A população brasileira já deixou de ser uma população de jovens, e o envelhecimento começa a ter uma visão mais gradual, ocorre também em escala mundial. Quando se eleva a melhoria na qualidade de vida das pessoas, conseqüentemente aumenta a expectativa de vida da população.

Reforçando os direitos fundamentais da terceira idade, estão reconhecidos também os de direitos de solidariedade ou fraternidade, que incluam o direito a um meio ambiente tranqüilo, saudável para a qualidade de vida, levando ao crescimento dessa geração, a sua autonomia, sobre os seus direitos regulamentados pela lei.

Discutir qualidade de vida é importante nos campos de conhecimento, para poder construir maneiras de considerar o indivíduo em diversas dimensões. Nem sempre é responsabilidade apenas do idoso ter qualidade de vida, basta lembrar que para ter ou não qualidade de vida existe fatores que podem contribuir e interferir na vida do idoso como condições financeiras sociais e culturais podem estar no processo de bem estar do mesmo.

Significa que é necessário dar oportunidades de participação a todos, que conceda saúde, cultura, lazer e assistência de qualidade a toda a população, construindo pesquisas e mobilizações para transformar em ações aqueles que necessitam de atendimento e repensar nas políticas e programas de ações destinadas aos idosos. 
Por fim, discutir qualidade de vida exige a preocupação de ajustar a vida com comprometimento com todas as gerações. O que se espera que ao chegar ao momento de desfrutar de uma velhice saudável, que seja possível obter de forma igualitária a todos.

Como um atributo inerente a cada ser humano, pelo simples fato de sermos pessoas, a dignidade da pessoa humana é indispensável para o reconhecimento dos direitos fundamentais objetivamente considerados pelo ordenamento jurídico. Independentemente de características físicas, psicológicas, morais e sociais não se perde ao decorrer da vida. Portanto, conforme estipula a Constituição Federal de 1988 em seu art. 5, caput, a vida é o imperativo constitucional, o alicerce de todo o direito individual. Por ser um bem jurídico indisponível, sem o qual não há personalidade jurídica, justifica a sua proteção pelo Estado ensejando assim o envelhecimento como um processo biológico que requer respeito.

Como conseqüência lógica tem-se a liberdade, o livre arbítrio para o idoso alcançar seus objetivos pessoais englobando vários direitos enumerados pela Constituição, tais como: a faculdade de ir, vir no território nacional, salvo restrições legais (art. $5^{\circ}, \mathrm{XV}$, da $\mathrm{CF}$ ); a liberdade de pensamento, a qual proíbe ao Estado censurar ou direcionar a atividade intelectual desde que não excessivamente imoral ou contrário aos bons costumes (art. $5^{\circ}$, VIII), bem como a liberdade de crença e de culto religioso (art. 5, IV, V, VI e VIII).

$\mathrm{O}$ art. 217, da referida constituição, determina que Poder Público propicie meios adequados para a prática de esportes e atividades que gerem diversões, visto que envelhecer acarreta desgastes físicos e psíquicos. Para a concretização de tais direitos citados a Lei 10.098/00, regulamentada pelo Decreto Federal 5.296/04, garante para aqueles com dificuldades de locomoção a acessibilidade aos meios de transporte, aos prédios públicos e privados, às ruas, calçadas e praças, por meio de rampas, portas mais largas, barras em corredores e banheiros com qualquer adaptação indispensável para facilitar a mobilidade, pois cabe ao idoso a garantia de um meio ambiente acessível.

Por fim, há liberdade de participar na vida familiar e comunitária com a inequívoca necessidade do afeto do seio familiar. O Estatuto do Idoso estipula em seu art. 10 a inviolabilidade da integridade física, psíquica e moral, acobertando a imagem, identidade, autonomia, valores, idéias, crenças, espaços e objetos pessoais dos idosos.

Portanto a pessoa natural e jurídica responde por atos que lhes causarem atordoações por danos morais e materiais. A imagem por representar o aspecto subjetivo da honra é relevante na interferência no âmbito social, pois a experiência idosa é exemplo para os demais, constituindo um direito personalíssimo e difuso da população idosa. 
Quanto à saúde a sua precariedade afeta de um modo mais intenso a pessoa idosa em função de sua maior vulnerabilidade, deste modo acarreta críticas às políticas públicas as quais disponibilizam uma prestação de serviço inadequados. A taxa de envelhecimento brasileiro aumenta a cada ano em função da redução da taxa de fecundidade, mortalidade e aumento da expectativa de vida exigindo para acesso integral à saúde as seguintes ações (art. 15, Lei 10741/2003): cadastro da população idosa no local de residência, atendimento geriátrico e gerontológico em ambulatórios públicos, criação de unidades geriátricas com pessoal especializado, estimulação ao atendimento domiciliar independentemente de se localizar em zona rural ou urbana e condição social, disponibilizar meios para a reabilitação e atendimento especial aos portadores de deficiência e aqueles com limitações físicas e psíquicas.

A proteção á saúde é de responsabilidade solidária do Poder Público, isto é, quando há ineficiência na prestação de atendimento com todas as suas conseqüências a lei (art. 196, CF e Lei 10741) possibilita ajuizado de ação em face de um, mais de um ou de todos os entes federativos (União, Estados, Distrito Federal e Municípios) sem prejuízo da também responsabilidade na esfera penal. Exige-se a participação do Ministério Público na fiscalização e cumprimento dessas decisões judiciais que determinam o aceso universal e igualitário a prevenção, promoção, proteção e recuperação incluindo fornecimento remédios, próteses, ortéses e demais recursos para tratamento de modo gratuito.

Vale salientar que é pacífico na doutrina e jurisprudência essa exigência nos sistemas público e privado de saúde. Quanto ao sistema privado o art. $15, \S 3^{\circ}$ do Estatuto do Idoso veda reajuste nas mensalidades após a pessoa completar idosos de modo indiscriminado e sem pré-aviso além de cláusulas abusivas, posto que quase a totalidade dessa população possua capital insuficiente para suportar os encargos dos planos de saúde.

No entanto a obrigação de alimentar como direito personalíssimo incluindo os denominados alimentos civis (aqueles estipulados judicialmente na proporção que acostumava ter anteriormente a referida necessidade, art. 1694, Código Civil) e naturais (abrangendo todas as necessidades vitais - alimentos, vestuário, remédios, água, luz, gás, etc.) destina-se aos cônjuges, companheiros, ascendentes, descendentes e irmãos. Faculta-se ao idoso escolher em face de quem ajuizará essa obrigação alimentícia cabendo ação regressiva quanto aos demais já que consiste numa obrigação solidária. Contudo, ausentes os parentes ou presentes e se o idoso não possui condições financeiras caberá ao Estado suprir essa falta. Essa determinação legislativa ocorrerá pelo recebimento de um salário-mínimo, a partir dos 65 anos, o 
denominado BPC (Benefício de Prestação Continuada) conforme o art. 20 da Lei Orgânica de Assistência Social - LOAS e art. 34 do Estatuto do Idoso. Salienta-se que tal benefício não requer contribuição haja vista a situação de carência que se encontra seu destinatário.

A legislação que recai sobre esta população, também se dispõe de deveres, como se nota quando há plena capacidade laborativa para se sustentar assim como aqueles seus dependentes, filhos e netos, por exemplo.

O Capítulo VI do Estatuto do Idoso da referida lei discorre sobre a profissionalização e o acesso ao trabalho, sendo assim superada está a idéia de que apenas a força jovem está apta a trabalhar para sobreviver e portanto, respeitadas os atributos físicos e psíquicos o idoso possui total capacidade laborativa ( arts. 26 a 28 , Lei 10741/2003 e arts. $1^{\circ}, \mathrm{IV}, 7^{\circ}, \mathrm{XXX}$ e 40 , $\left.\S 1^{\circ}, \mathrm{CF}\right)$.

Sendo assim, É necessário que se faça o aprimoramento da capacidade funcional do profissional idoso incluindo o ingresso a faculdades e as novas tecnologias disponíveis no mercado, por meio de programas condizentes às suas características e expectativas. É proibida a discriminação e a fixação de limite máximo de idade para admissão em qualquer emprego ou trabalho, tal disposição objetiva ampliar as oportunidades de trabalho.

Em decorrência do art. 194 da Magna Carta assistem à pessoa idosa a previdência social (Seguridade Social consiste assegurar direitos referentes à saúde, à previdência social e à assistência social). É um seguro que propicia renda do contribuinte e seus dependentes em casos de doenças, acidente, gravidez, prisão, morte e velhice surgindo à necessidade de se inscrever e contribuir mensalmente.

O Estatuto do Idoso com base no Regime Geral da Previdência Social, ou seja, aquele destinado aos trabalhadores da iniciativa privada e aos servidores do setor públicos, tem o INSS como órgão executivo, estipula que se deve preservar o valor real dos salários sobre os quais incidirão as respectivas contribuições. Deve se solicitar esse benefício por meio de agendamento prévio pelo portal da Previdência Social na Internet, pelo telefone 135 ou nas Agências da Previdência Social, mediante o cumprimento das exigências legais (idade mínima e carência de 180 contribuições mensais ).

No rol dos direitos fundamentais destinados à pessoa idosa há a gratuidade nos transportes públicos e privados englobando os transportes rodoviário, ferroviário, aquaviário, marítimo e aéreo a partir dos 65 anos de idade, além da determinação de $10 \%$ dos assentos de cada veículo ser lhes reservados (art. 39 do referido Estatuto e art. 230, $\S 2^{\circ}, \mathrm{CF}$ ). O transporte interestadual impõe-se a reserva de duas vagas por veículo para os possuidores de 
renda igual ou inferior a 2 salários-mínimos e também, a concessão de 50\% de desconto, no mínimo, no valor da passagem, salienta-se a comprovação da idade e falta de recursos.

Por fim, quanto ao transporte intermunicipal a legislação é omissa existindo casos em que há decisões concedendo ou não a gratuidade ocasionando assim, insegurança jurídica. Esse direito inclui vagas privativas em estacionamentos de estabelecimentos públicos e privados num percentual 5\% com o intuito de dar ao ancião comodidade em sua locomoção em observância às suas atribuições.

Há também a faculdade do idoso requerer perante o Juiz de Direito a prioridade na tramitação processual conforme determina o art. 71 da Lei 10741/ 2003 demonstrando sua idade superior a 60 anos abrangendo os processos judiciais e administrativos, além daqueles decorrentes de empresas e instituições prestadoras de serviços públicos no âmbito federal, estadual e municipal. Esse direito não desobriga aos deveres e ônus processuais que todo processo acarreta.

A habitação também possui prioridade aos idosos com programas para a sua concretização atribuídos à Habitação de Interesse Social para a população de baixa renda, já que a propriedade é um direito público subjetivo para o desenvolvimento de cada ser humano independente da idade. De nada vale esses direitos se não se incluir o acesso à educação posto que a sua procura caracterize um meio de inserção social para a sociedade que o estigmatiza.

A vida é um constante aprendizado, portanto, inclusão do idoso no espaço de ensino é, sem dúvida, o caminho para diminuir os pré-conceitos e esteriotipações vinculados à sua imagem. Para tanto, adequar os currículos, metodologias e matérias didáticas configuram meios para alfabetização e especialização desse segmento de pessoas.

Entretanto, não há estrutura apropriada para atender à demanda como ocorre nas Universidades Abertas à Terceira Idade. O problema também ocorre no tocante ao sistema educacional brasileiro que prioriza ensinar crianças, adolescentes e adultos resultando a exclusão.

A demonstração do respeito para os idosos é preciso estar introduzidos em ações do dia a dia. Reclamar da presença dos idosos e extenuar atos e ações que destacam o idoso de forma repressora desencadeia ações erradas, que podem passar adiante. A educação nasce dentro do seio familiar, parte de princípios existentes na família. 
Trabalhar a temática, é a forma pensada de reforçar a prática, é a forma de explicar sobre as ações corretas a serem seguidas. Fazer-se entender que a vida é um ciclo e que a velhice faz parte da condição humana, e que todos irão passar por esse ciclo.

Explicar as crianças e/ou adolescentes sobre o Estatuto do Idoso é de certa forma, esclarecer não somente os direitos, mas também demonstrar como devem ser cumpridos e dar garantia aos idosos, pois demonstrar como devemos respeitar os idosos é fundamental na formação da criança e/ou adolescente, ambas as gerações passam a refletir sobre a possibilidade de mudanças quanto à percepção da velhice e do envelhecimento.

As atividades intergeracionais têm como objetivo trabalhar de forma educativa a realização das atividades entre as crianças e/ou adolescente, como eixo condutor da comunicação intergeracional e do processo de conscientização dos problemas da velhice e do envelhecimento com o intuito de fomentar a comunicação intergeracional.

\section{FORMANDO CIDADÃOS}

O NASJEPI- Núcleo Assistência Social, Jurídica e de estudos sobre a Pessoa Idosa é um projeto de extensão da UEPG- Universidade Estadual de Ponta Grossa, coordenada pela Prof. ${ }^{a}$ Msc. Maria Iolanda de Oliveira, em Serviço Social, Ma. Andressa Pacenko Malucelli, em Direito, sendo a equipe composta por (01) Assistente Social, (03) acadêmicas do curso de Serviço Social e (01) acadêmica do curso de Direito.

Dentre as atividades e temáticas de estudo do NASJEPI, são realizados ações como oficinas e palestras voltadas a divulgação do Estatuto do Idoso, informações sobre questões jurídicas e de assistência social e ainda estudos e produções de artigos e materiais voltados à temática.

As oficinas supracitadas são realizadas em escolas de ensino fundamental, onde se aborda temas como: processo de envelhecimento, a importância de conhecer para respeitar os direitos fundamentais da pessoa idosa, bem como os demais, previstos na Lei N. 10.741 de 1 . $^{\circ}$ de outubro de 2003 que dispõe o Estatuto do Idoso.

No primeiro momento da oficina, é sugerido aos alunos que caracterizem através de seu entendimento um desenho sobre a pessoa idosa. A partir disso, inicia-se a discussão sobre o qual é o papel da pessoa idosa na sociedade e o que ele representa. Ao serem indagados, os participantes geralmente demonstram já conhecer à temática, através da mídia e de redes sociais. 
Dando continuidade na oficina a equipe NASJEPI aborda temas como: inclusão social, o aumento da população idosa, as relações intergeracionais, envelhecimento como processo natural da vida, dentre outros assuntos.

O objetivo principal da equipe é proporcionar aos alunos uma reflexão sobre as dificuldades enfrentadas pela pessoa idosa no cotidiano, levantando questionamento de como é tornar-se uma pessoa idosa na contemporaneidade. Outra questão relevante é a abordagem através de vídeos e interpretações, sobre violência contra a pessoa idosa, onde destacamos as violências : psicológica, física, verbal e financeira, sendo situações que envolvem o idoso.

São apresentados ainda na sequência da oficina dados estatísticos em relação ao aumento da população idosa, bem como a expectativa e a qualidade de vida. Todas as atividades e explanações são realizadas de forma lúdica, utilizando diversos objetos e jogos que se adéquam à temática.

Ao Finalizar a oficina e como forma de analisar o aproveitamento dos conteúdos aplicados, é proposto aos participantes que, avaliem a oficina trabalhada que leva como tema "Direito dos Idosos: conhecer para respeitar".

\section{CONSIDERAÇÕES FINAIS}

Ao trabalharmos o Estatuto do Idoso, relacionando os direitos foi possível abordar o atual processo de envelhecimento populacional, pautando a relação das crianças e adolescentes com as pessoas idosas. Ao abordar as diversas formas de violência contra a pessoa idosa, percebeu-se que os participantes têm conhecimento sobre esse fato que ocorre aos idosos.

Por isso, os parâmetros dessas discussões servem como forma de construirmos uma cidadania, em promoção as questões de direitos aos idosos, as suas ações e omissões que podem contrariar os direitos e a incapacidade de dar a garantia aos idosos.

O respeito depende da conscientização de cada cidadão que, um dia também irá envelhecer e temos um tempo para refletirmos e pensarmos como iremos envelhecer. Afinal, respeito é necessário para uma boa convivência. Ainda que haja uma distância entre o que garante o Estatuto e o que de fato ocorre, faz- se necessário questionar o tema, e levá-lo a espaços que podem ser entendidos e interpretados. 
Assim, a discussão da noção do exercício de direitos mostra-se fundamental no entendimento de todas as classes para um reconhecimento social enquanto atores independentes e ativos.

O Estatuto do Idoso é apenas um dos seguimentos que envolvem os direitos humanos, sendo assim, a pessoa idosa é digna de reconhecimento não só pelo fato de possuir direitos, mas também pela sua integralidade na sociedade, que os torna cidadãos ativos.

Nesse sentido constata-se a importância de implementação do Estatuto como objeto de referências dos direitos humanos no que tange a pessoa idosa. Partindo desse principio, é de fundamental relevância a aplicação da lei nas escolas de ensino fundamental, que fará com que crianças e/ou adolescentes utilizem-se deste conhecimento como processo de formação social e transformação a criação de novas imagens sobre a velhice.

\section{REFERÊNCIAS}

ANTONIO IBRAHIM, Marco. Direito ao respeito.

Disponível em:

$<$ http://www.ambitojuridico.com.br/site/index.php?n_link=revista_artigos_leitura\&artigo_id= 2 039>

Acesso em: 05 set. 2013

ARAÚJO, Alyane Almeida de. O direito ao trabalho e a à profissionalização do idoso. Disponível em:

$<$ http://www.trt21.jus.br/ej/revista/2005/doutrina_direitoaotrabalho_iframe.htm>. Acesso em 05 set. 2013

BRASIL. Estatuto do Idoso. Ministério da Saúde, Brasília, DF, 2003.

DALlARI, Dalmo Abreu. O que são direitos da pessoa. São Paulo: Abril Cultural: Brasiliense, 1984.

FREITAS JUNIOR, Roberto Mendes de. Direitos e garantias do idoso: doutrina, jurisprudência e legislação. 2 ed. São Paulo: Atlas, 2011.

MORAIS, Edgar Nunes de. Atenção à saúde do idoso: Aspectos conceituais.

Disponível em:

< http://apsredes.org/site2012/wp-content/uploads/2012/05/Saude-do-Idoso-WEB1.pdf>.

Acesso em: 05 set. 2013

NASCIMENTO, José do. Os direitos Humanos e sua Articulação com os Sistemas Sociais. Editora UCDB. Campo Grande - MS UCDB, 2001. 
Rev. Triang. v. 7, n. 2:93-105, jul./dez. 2014 106

NASJEPI. Núcleo de Assistência Social, Jurídica e de estudos sobre a pessoa idosa. Ponta Grossa, Paraná. 2010.

SIQUEIRA JR, Paulo Hamilton; OLIVEIRA, Miguel Augusto Machado. Direitos Humanos e Cidadania. 2. ed. São Paulo: Revista dos Tribunais, 2009.

RECEBIDO EM: 20/09/2013.

APROVADO EM: 23/09/2015. 